\title{
FISM and FMICMAC Analysis on Enablers of Cloud Computing
}

\author{
Ambika Devi Amma.T \\ Research Scholar Karpagam \\ University. (Professor, Dept .of \\ Computer Science \&Engg, NSS \\ College of Engineering, \\ Palakkad, Kerala, India 678008
}

\author{
Radhika.N,Ph.D \\ Associate Professor, \\ Computer Science \& Engg Dept, \\ Amrita University, Coimbatore, \\ TamilNadu, India 641105
}

\author{
Pramod.V.R, Ph.D \\ Associate. Professor, \\ Dept. of Mechanical \\ Engineering, NSS College \\ of Engg, Palakkad, Kerala, \\ India 678008
}

\begin{abstract}
Cloud computing is an automatic multitenant pay-as-you go service accessed through web browsers. . The main services of cloud computing are software as a service, infrastructure as a service and platform as a service. These services are very much helpful and beneficial to IT organizations undergoing severe budgetary constraints. In this paper the major enablers of cloud computing services are taken by discussing with experts and through literature survey. An interrelation ship among the enablers are done with FISM(Fuzzy Interpretive Structural Modeling and FMICMAC(Fuzzy MICMAC) analysis. An initial reachability set is constructed from structural self interaction matrix (SSIM) and final reachability set by considering a scale $0-1$ instead of binary condition. Enablers chosen are classified into four clusters based on their driving power and dependence power. From MATLAB FISM model is derived. This paper highlights the most sensitive enablers of cloud computing services.
\end{abstract}

\section{Key words}

Cloud, fuzzy ISM, fuzzy MICMAC, SSIM, driving power, dependence power.

\section{INTRODUCTION}

Cloud computing is a new technology in which the user can make use of its services by giving an amount for usage. This technology has visualized environment and is primarily driven by the internet with rapid provisioning of resources and high scalability. Cloud computing describes the means of delivering all information like computing power applications, infrastructure to end user as a service. Without understanding the underlying technology it allows people to do things that they need from cloud. It manages a large number of highly virtualized resources. Cloud computing help IT field by reducing the capital expenditure and operational expenses. It impresses quality of services by delivering new services that help the industries to grow and reduce the initial investment cost. Cloud computing is considered as service over the internet for the provision of dynamically scalable and often visualized resources. Cloud computing can be considered as massively scalable, self service delivery model to access networking, processing storage and application as a service with the help of a web browser. The process is automated so that the operating cost can be reduced. Today cloud service is user friendly and offered an unprecedented scale. The service can be obtained as pay as you go and pay for what you use. The customers don't need an upfront investment or a long term contract. The reason behind the adoption of cloud are web scale abstracted infrastructure, dynamic allocation, pay as you go, no long term commitment operating system, application architecture independent and no hardware or software to install. Cloud environment is self service, selfprovisioning and rapid provisioning. The clouds get efficiency by virtualization. It provide utility pricing, variable payment, pay by use with metering and subscription. The virtualization and consolidation reduces operating costs, improve responsiveness. Information infrastructure helps business to achieve information compliance and security. The base of cloud computing is commodity based hardware and software. Without affecting the cloud services the hardware can be replaced at anytime. The service should be able to move from one cloud service provider to any other cloud service provider without affecting the service. Cloud requires virtualization engine and an abstraction layer for software and hardware configuration. Multiple customers share infrastructure resources without compromising the privacy and security of data. Based on the capacity needed the service delivery infrastructure expands and contracts automatically i.e. cloud service is elastic in nature. Cloud delivers software platform through intelligent resources allocation policies and by the usage of physical and virtual infrastructure. Resource aggregation and integration is one of the high level capabilities of the cloud. Application services range from individual machines to full multitier environment consisting of collection of machines. Self-service access is one of the important principles of cloud. Automated allocation of resources is carried out with dynamic resource management. Dynamic resource management maximizes the efficiency of IaaS infrastructure. Using an accounting database the metering information on resources allocations and actual usage are accounted.

Some of the features of the cloud are discussed herewith. Self service is one of the important features of the cloud. Using role-based access control it separate authenticated endusers. Dynamic workload management enables the datacenters with automation. Resource automation establishes secure multitenency and helps prevent contention in the load aware resource engine. Enabling the feature charge back, show back and metering the transparency in cloud business is attained. Cloud is integrated with the products in the datacenter. It is possible to meter the cloud resource usage. Cloud support most of the operating systems and is possible to vary hardware configuration. Role-based access administrations are used for providing secure multitenency and bring security to the self-service cloud portal.

The cloud enables automated delivery of applications. Fully configured multi-component application environment could be delivered to users work the cloud model thereby increasing the user efficiency. Customer datacenter can use resource in 
public cloud if there are no resources available on these premises which help them to differ from new hardware procurement. Cloud computing will enhance the enterprises by reducing the administer numbers cycle times to provision new assets, in planned capital spending and maintains and in physical server count. Cloud will help the enterprises by using consumption based charge back i.e. (pay-as-you-go).Cloud deployment models are public cloud, private cloud and hybrid cloud. Public cloud services are available to customers from a third party service provider via the internet. Public clouds provide cost-effective means to deploy solutions. Companies can use it on demand and with the pay-as-you use policy Private clouds are deployment made inside the on-premise data centers and run by on site servers. Like public cloud private cloud offers cloud computing environment such as elastic on demand capacity, self service provisioning and service based access. Hybrid cloud is a combination of interoperating public and private clouds. Hybrid models allow elasticity pay- as- you -go pricing, network isolation and secure connectivity just like privately owned data centre.

Cloud computing provides massively scalable computing resources from anywhere simplifies service delivery. It provides rapid innovation and dynamic platform for next generation datacenters. The major enablers are shown in Table1.

\section{Table 1. Major enablers of cloud computing}

\begin{tabular}{|l|l|l|}
\hline $\begin{array}{l}\text { Enabler } \\
\text { number }\end{array}$ & $\begin{array}{l}\text { Major enabler of cloud } \\
\text { computing }\end{array}$ & References \\
\hline 1 & Data protection & {$[1],[2]$} \\
\hline 2 & Confidentiality & {$[1],[2]$} \\
\hline 3 & Data integrity & {$[1],[2]$} \\
\hline 4 & Data availability & {$[1],[2]$} \\
\hline 5 & Multitenency & {$[1],[2]$} \\
\hline 6 & Operational efficiency & {$[1],[2]$} \\
\hline 7 & Elasticity & {$[1],[2]$} \\
\hline 8 & Interoperability & {$[1],[2]$} \\
\hline 9 & Authorization & {$[1],[2]$} \\
\hline 10 & Auditing & {$[1],[2]$} \\
\hline 11 & Guidance & {$[1],[2]$} \\
\hline 12 & Standards & {$[1],[2]$} \\
\hline 13 & Data lineage & {$[1],[2]$} \\
\hline 14 & Data reminisce & {$[1],[2]$} \\
\hline 15 & Data provenance & {$[1],[2]$} \\
\hline & & \\
\hline
\end{tabular}

A brief enumeration of the enables are given below

1 Data protection:- Data available in cloud should be protected from external attacks

2 Confidentiality:-All datas should have authentication and authorization for protection and encryption

3 Data integrity: -data should not be changed in an unauthorized manner.

4 Data Availability:- Data should be available to support the operations.
5 Multitenancy:- Sharing of same resources across a large pool of customers.

6 Operational Efficiency:- Efficiency of operation depends on the interfaces and web connection, availability of data.

7 Elasticity: -Application can expand and contract on demand

8 Interoperability:- Provision to operate different clouds in different countries.

9 Authorization: -To manage user accounts and various assurance.

10 Auditing;- keeping the account of usage of consumers.

11 Guidance: -Handling identity and access management.

12 Standards:- Standards are defined by governing body or a market lead. It scarce as cloud is concerned.

13 Data lineage:- following the path of data.(mapping application data flows or data path visualization)

14 Data remanence:- is the residual representation of data that has been in some way erased or removed.

15 Data provenance: -Data has integrity and computationally accurate.

\section{LITERATURE SURVEY.}

Cloud computing is becoming a well known buzz word now a days. Privacy issues and security problems are pointed out as barriers for users to adopt into cloud computing systems. Users of cloud computing worry about their business informations and critical IT resources in the cloud computing systems which are vulnerable to be attached [1]. Cloud computing allows providers to develop, deploy and run applications that can easily grow in capacity work rapidly without any concern on the properties and the locations of the undergoing infrastructures[2]. Availability is one of the goals of security. It ensure the user to use them at any time at any place. Hardening and redundancy will enhance the availability of the cloud system. Many cloud computing system provide cloud infrastructure and platforms based on virtual machine [Farzad Sabahi,2011] Confidentiality means keeping user's data secret in the cloud system.

Data integrity means prurience the information. No change or no modification by unauthorized users. Access control is another good in security. Access control means to regulate the use of the system including applications, infrastructure and data. Auditing is another phenomena that could be added as an additional layer above the virtualized OS hosted on the virtual machine [7].Secret information of individual users and business are stored and managed by the service providers.

Cloud computing raises a range of important policy issues, which include issues of Privacy, security, anonymity, telecommunications capacity, government surveillance, reliability, and liability, among others. Users will expect 
Reliability and Liability on the cloud service resource. Especially if a cloud provider takes over the task of running "mission-critical" applications and will expect clear delineation of liability if serious problems occur. Users will expect that the cloud provider will prevent unauthorized access to both data and code, and sensitive data will remain private. Users will expect to be able to access and use the cloud where and when they wish without hindrance from the cloud provider or third parties, while their intellectual property rights are upheld. Each of these interrelated issues will be considered in terms of its importance, what realistic expectations users might have, and the policy implications.

S. Pearson et al describes privacy manager mechanism in which user's data is safe on cloud, in this technique the user's data is in encrypted form in cloud and evaluation is done on encrypted data, the privacy manager make readable data from result of evaluation manager to get the correct result. In obfuscation data is not present on Service provider's machine so there is no risk with data, so data is safe on cloud, But this solution is not suitable for all cloud application, when input data is large this method can still require a large amount of memory[2]. In [3], the authors present procedural and technical solution both are producing solution to accountability to solving security risk in cloud in this mechanism these policies are decided by the parties that use, store or share that data irrespective of the jurisdiction in which information is processed. But it has limitation that data processed on SP is in unencrypted at the point of processing so there is a risk of data leakage. In [4], the author gives a language which permits to serve data with policies by agent; agent should prove their action and authorization to use particular data. In this logic data owner attach Policies with data, which contain a description of which actions are allowed with which data, but there is the problem of Continuous auditing of agent, but they provide solution that incorrect behavior. Should monitor and agent should give justification for their action, after that authority will check the justification. In [5], authors gives a three layer architecture which protect information leakage from cloud, it provides three layer to protect data, in first layer the service provider should not view confidential data in second layer service provider should not do the indexing of data, in third layer user specify use of his data and indexing in policies, so policies always travel with data. In [6], authors present accountability in federated system to achieve trust management. The trust towards use of resources is accomplished through accountability so to resolve problem for trust management in federated system they have given three layers architecture, in first layer is authentication and authorization in this authentication does using public key cryptography. Second layer is accountability which perform monitoring and logging. The third layer is anomaly detection which detects misuse of resources. This mechanism requires third party services to observe network resources.

Interpretive structural modeling is a well established methodology for identifying relationships among elements present in a complex structures [15]. ISM is an interactive learning process in which set of directly or indirectly related elements are structured into a comprehensive model. For identity relationships among items, the ism methodology can be established. The variables in the specific problem or issue is identified first and then a contextually relevant subordinate relation is taken. Based on pair-wise comparison of variables, a structural self interaction matrix (SSIM) is developed from the element set. Transitivity is checked and a matrix model is obtained. ISM is derived from the partitioning of the element and an extractive of the structural model [10]. In this approach conceptual and computational leverage are exploited to explain the contextual relationship among a set of variables. According to Warfield [11] a set of requirement are needed for interpretive structural modeling.

They are: a) Inclusion of scientific elements b) A complex set of relation can be exhibited c) Complex set of relations permits continuous observation, questioning and modification d) Consequence with perceptions and analytical process of the originators e) Public audience can early learn.

\section{METHODOLOGY.}

Fuzzy ISM is an advanced methodology compared to ISM. ISM is an interpretive structural methodology used for deciding the interrelationship of different elements in a system. An overall structure is extracted from the set of elements hence it is structural on the basis of mutual relationships and the overall structure are portrayed in a diagraph model hence it is a modeling technique. The elements order and their direction on the complexity of relationship can be studied with the help of ISM [11 ]. Warfield uses elementary notions of graph theory and Boolean algebra so as to implement a man made interactive model. ISM is a learning process for finding the inter relationship between variables of a system. ISM has predefined steps for achieving the results. For obtaining the interrelationship among the variables ISM uses binary number 0 and 1.0 is used for no relation and 1 for having the relation. In fuzzy ISM an additional input of possibility of interaction is on $0-1$ scale avoiding $0 \& 1$.

\subsection{Development of fuzzy ISM}

Based on contextual relationship among enablers a structural self interaction matrix is developed A pair-wise relationship among the enablers are carried out. Assuming i\& $j$ are the element then the symbol $\mathrm{V}$ denotes that $\mathrm{i}$ will help to achieve $\mathrm{j}$. The symbol A denotes that $\mathrm{j}$ will help to achieve $\mathrm{i}$. The symbol $\mathrm{X}$ means $\mathrm{i} \& \mathrm{j}$ will help each other to achieve. $\mathrm{O}$ means i \& j are unrelated. Structural self interaction matrix is shown in Table 2.

The rules for achieving initial reachability matrix from structural self interaction matrix (SSIM) are given below

1). If the (i, j) entry in SSIM is $V$, then (i, j) entry in the adjacency matrix is 1 and (j.i) entry is 0.2 .) If the (i.j) entry in SSIM is A, then ( $i, j)$ entry in the adjacency matrix is 0 and (j.i) entry is 1 .

3). If the (i.j) entry in SSIM is $X$, then (i, j) entry in the adjacency matrix is 1 and (j.i) entry is 1 .

4.) If the (i.j) entry in SSIM is $O$, then (i, j) entry in the adjacency matrix is 0 and (j.i) entry is 0 .

The initial reachability matrix is constructed based on the above rule and is shown in Table 3. Then final reachability matrix is constructed by considering an additional input of 0-1 scale avoiding transitivity. Final reachability matrix is shown in Table 4. 
Table 2: structural Self Interaction Matrix (SSIM)

\begin{tabular}{|c|c|c|c|c|c|c|c|c|c|c|c|c|c|c|c|}
\hline & & 15 & 14 & 13 & 12 & 11 & 10 & 9 & 8 & 7 & 6 & 5 & 4 & 3 & 2 \\
\hline 1 & Data protection & $\mathrm{O}$ & $\mathrm{O}$ & $\mathrm{O}$ & $\mathrm{O}$ & $\mathrm{O}$ & $\mathrm{O}$ & $\mathrm{V}$ & A & $\mathrm{V}$ & $\mathrm{O}$ & $\mathrm{O}$ & $\mathrm{A}$ & $\mathrm{A}$ & $\mathrm{V}$ \\
\hline 2 & Confidentiality & $\mathrm{O}$ & $\mathrm{O}$ & $\mathrm{O}$ & $\mathrm{O}$ & $\mathrm{O}$ & $\mathrm{O}$ & $\mathrm{A}$ & $\mathrm{O}$ & $\mathrm{O}$ & $\mathrm{O}$ & $\mathrm{O}$ & $\mathrm{V}$ & $\mathrm{O}$ & \\
\hline 3 & Data integrity & $\mathrm{O}$ & $\mathrm{O}$ & $\mathrm{O}$ & $\mathrm{O}$ & $\mathrm{O}$ & $\mathrm{O}$ & $\mathrm{O}$ & $\mathrm{O}$ & $\mathrm{A}$ & $\mathrm{V}$ & $\mathrm{O}$ & $\mathrm{V}$ & & \\
\hline 4 & Data availability & $\mathrm{O}$ & $\mathrm{O}$ & $\mathrm{V}$ & $\mathrm{O}$ & $\mathrm{O}$ & $\mathrm{O}$ & $\mathrm{O}$ & $\mathrm{O}$ & $\mathrm{V}$ & $\mathrm{V}$ & $\mathrm{A}$ & & & \\
\hline 5 & Multitenency & $\mathrm{O}$ & $\mathrm{O}$ & $\mathrm{O}$ & $\mathrm{O}$ & $\mathrm{O}$ & $\mathrm{O}$ & $\mathrm{O}$ & $\mathrm{V}$ & $\mathrm{V}$ & $\mathrm{V}$ & & & & \\
\hline 6 & Operational efficiency & $\mathrm{O}$ & $\mathrm{O}$ & $\mathrm{O}$ & $\mathrm{O}$ & $\mathrm{V}$ & $\mathrm{O}$ & $\mathrm{O}$ & $\mathrm{V}$ & $\mathrm{A}$ & & & & & \\
\hline 7 & Elasticity & $\mathrm{O}$ & $\mathrm{O}$ & $\mathrm{O}$ & $\mathrm{A}$ & $\mathrm{O}$ & $\mathrm{O}$ & $\mathrm{O}$ & $\mathrm{V}$ & & & & & & \\
\hline 8 & Interoperability & $\mathrm{O}$ & $\mathrm{O}$ & $\mathrm{O}$ & $\mathrm{V}$ & $\mathrm{O}$ & $\mathrm{O}$ & $\mathrm{O}$ & & & & & & & \\
\hline 9 & Authorization & $\mathrm{O}$ & $\mathrm{O}$ & $\mathrm{O}$ & $\mathrm{O}$ & $\mathrm{V}$ & $\mathrm{X}$ & & & & & & & & \\
\hline 10 & Auditing & $\mathrm{O}$ & $\mathrm{A}$ & $\mathrm{A}$ & $\mathrm{O}$ & $\mathrm{V}$ & & & & & & & & & \\
\hline 11 & Guidance & $\mathrm{O}$ & $\mathrm{O}$ & $\mathrm{O}$ & $\mathrm{A}$ & & & & & & & & & & \\
\hline 12 & Standards & $\mathrm{O}$ & $\mathrm{O}$ & $\mathrm{O}$ & & & & & & & & & & & \\
\hline 13 & Data lineage & $\mathrm{A}$ & $\mathrm{V}$ & & & & & & & & & & & & \\
\hline 14 & Data reminisce & $\mathrm{V}$ & & & & & & & & & & & & & \\
\hline 15 & Data provenance & & & & & & & & & & & & & & \\
\hline
\end{tabular}

Table3. Initial Reachability Matrix

\begin{tabular}{|c|c|c|c|c|c|c|c|c|c|c|c|c|c|c|c|}
\hline & 1 & 2 & 3 & 4 & 5 & 6 & 7 & 8 & 9 & 10 & 11 & 12 & 13 & 14 & 15 \\
\hline 1 & 1 & 1 & 0 & 0 & 0 & 0 & 1 & 0 & 1 & 0 & 0 & 0 & 0 & 0 & 0 \\
\hline 2 & 0 & 1 & 0 & 1 & 0 & 1 & 0 & 0 & 0 & 0 & 0 & 0 & 0 & 0 & 0 \\
\hline 3 & 1 & 0 & 1 & 1 & 0 & 1 & 0 & 0 & 0 & 0 & 0 & 0 & 0 & 0 & 0 \\
\hline 4 & 1 & 0 & 0 & 1 & 0 & 1 & 1 & 0 & 0 & 0 & 0 & 0 & 1 & 0 & 0 \\
\hline 5 & 0 & 0 & 0 & 1 & 1 & 1 & 1 & 1 & 0 & 0 & 0 & 0 & 0 & 0 & 0 \\
\hline 6 & 0 & 0 & 0 & 0 & 0 & 1 & 0 & 1 & 0 & 0 & 1 & 0 & 0 & 0 & 0 \\
\hline 7 & 0 & 0 & 1 & 0 & 0 & 1 & 1 & 1 & 0 & 0 & 0 & 0 & 0 & 0 & 0 \\
\hline 8 & 1 & 0 & 0 & 0 & 0 & 0 & 0 & 1 & 0 & 0 & 0 & 1 & 0 & 0 & 0 \\
\hline 9 & 0 & 1 & 0 & 0 & 0 & 0 & 0 & 0 & 1 & 1 & 1 & 0 & 0 & 0 & 0 \\
\hline 10 & 0 & 0 & 0 & 0 & 0 & 0 & 0 & 0 & 1 & 1 & 1 & 0 & 0 & 0 & 0 \\
\hline 11 & 0 & 0 & 0 & 0 & 0 & 0 & 0 & 0 & 0 & 0 & 1 & 0 & 0 & 0 & 0 \\
\hline 12 & 0 & 0 & 0 & 0 & 0 & 0 & 1 & 0 & 0 & 0 & 1 & 1 & 0 & 0 & 0 \\
\hline 13 & 0 & 0 & 0 & 0 & 0 & 0 & 0 & 0 & 0 & 1 & 0 & 0 & 1 & 1 & 0 \\
\hline 14 & 0 & 0 & 0 & 0 & 0 & 0 & 0 & 0 & 0 & 1 & 0 & 0 & 0 & 1 & 1 \\
\hline 15 & 0 & 0 & 0 & 0 & 0 & 0 & 0 & 0 & 0 & 0 & 0 & 0 & 1 & 0 & 1 \\
\hline
\end{tabular}

Table4.Final Reachability Matrix

\begin{tabular}{|c|c|c|c|c|c|c|c|c|c|c|c|c|c|c|c|c|}
\hline & 1 & 2 & 3 & 4 & 5 & 6 & 7 & 8 & 9 & 10 & 11 & 12 & 13 & 14 & 15 & D P \\
\hline 1 & 1 & 1 & 0.9 & 0.9 & 0 & 0.7 & 1 & 0.8 & 1 & 0.9 & 0.8 & 0 & 0 & 0 & 0 & 9 \\
\hline 2 & 0.8 & 1 & 0 & 1 & 0 & 1 & 0.8 & 0 & 0 & 0 & 0 & 0 & 0 & 0 & 0 & 4.6 \\
\hline 3 & 1 & $\begin{array}{l}0.5 \\
\end{array}$ & 1 & 1 & 0 & 1 & 0.7 & 0 & 1 & 0 & 0 & 0 & 0 & 0 & 0 & 6.2 \\
\hline 4 & 1 & 0.7 & 0.7 & 1 & 0 & 1 & 1 & 0 & 0 & 0 & 0 & 0 & 0 & 0 & 0 & 5.4 \\
\hline 5 & 1 & 0 & 1 & 1 & 1 & 1 & 1 & 1 & 0 & 0 & 1 & 1 & 0 & 0 & 0 & 9 \\
\hline 6 & 0.9 & 0 & 0 & 0 & 0 & 1 & 0 & 0.6 & 0 & 0 & 0.8 & 0.9 & 0 & 0 & 0 & 4.2 \\
\hline 7 & 0.4 & 0 & 1 & 0.8 & 0 & 1 & 1 & 1 & 0 & 0 & 0 & 0 & 0 & 0 & 0 & 5.2 \\
\hline 8 & 1 & 0.3 & 0 & 0 & 0.9 & 0.8 & 0.7 & 0.7 & 0.8 & 0 & 0.7 & 1 & 0 & 0 & 0 & 6.9 \\
\hline 9 & 0 & 1 & 0 & 0.5 & 0 & 0 & 0 & 0 & 1 & 1 & 1 & 0 & 0 & 0 & 0 & 4.5 \\
\hline 10 & 0 & 0.7 & 0 & 0 & 0 & 0 & 0 & 0 & 1 & 1 & 1 & 0 & 0 & 0 & 0 & 3.7 \\
\hline 11 & 0 & 0 & 0 & 0 & 0 & 0 & 0 & 0 & 0 & 0 & 1 & 0 & 0 & 0 & 0 & 1 \\
\hline 12 & 0 & 0 & 0.8 & 0.3 & 0 & 0 & 1 & 0.9 & 0 & 0 & 1 & 1 & 0 & 0 & 0 & 5 \\
\hline 13 & 0 & 0.6 & 0 & 0 & 0 & 0 & 0 & 0 & 0.7 & 1 & 0.7 & 0 & 1 & 1 & 0.7 & 5.7 \\
\hline 14 & 0 & 0 & 0 & 0 & 0 & 0 & 0 & 0 & 1 & 1 & 0.6 & 0 & 0 & 1 & 1 & 4.6 \\
\hline 15 & 0 & 0 & 0 & 0 & 0 & 0 & 0 & 0 & 0 & 0.6 & 0 & 0 & 1 & 0.8 & 1 & 3.4 \\
\hline DEP & 7.1 & 5.8 & 5.4 & 6.5 & 1.9 & 7.5 & 7.2 & 5 & 6.5 & 5.5 & 8.6 & 3.9 & 2 & 2.8 & 2.7 & \\
\hline
\end{tabular}

\subsubsection{Level Partitions.}

From the final reachability matrix, the reachability set and antecedent set for each element is found. The reachability set consists of the elements and other elements which may help to achieve it. The antecedent set consist of the element and other elements which may help in achieving it. After getting reachability set and antecedent set an intersection set is derived for all elements. The element for which the reachability set and the intersection sets are same will occupy the top level in the ISM hierarchy- Table5 .The top level element would not help to achieve any other element above its own level .So top-level element is separated from other elements. The same process is repeated to find out the next 
level elements. This process will continue until the levels of all elements are found-Table 6. These levels are used for building ISM model-Figure1.

Table 5: $1^{\text {ST }}$ Level partition

\begin{tabular}{|l|l|l|l|l|}
\hline $\begin{array}{l}\text { Enabl } \\
\text { ers }\end{array}$ & Reachability set & Antecedent set & $\begin{array}{l}\text { Intersecti } \\
\text { on }\end{array}$ & $\begin{array}{l}\text { Lev } \\
\text { el }\end{array}$ \\
\hline 1 & $\begin{array}{l}1,2,3,4,6,7,8,9,1 \\
0,11\end{array}$ & $1,2,3,4,5,6,7,8$ & $\begin{array}{l}1,2,3,4,6, \\
7,8\end{array}$ & \\
\hline 2 & $1,2,4,6,7$ & $1,2,3,4,8,9,10,13$ & $1,2,4$ & \\
\hline 3 & $1,2,3,4,6,7,9$ & $1,3,4,5,7,12$ & $1,3,4,7$ & \\
\hline 4 & $1,2,3,4,6,7$ & $1,2,3,4,5,7,9,12$ & $1,2,3,4,7$ & \\
\hline 5 & $1,3,4,5,6,7,8,11$, & 5,8 & 5,8 & \\
& 12 & & & \\
\hline 6 & $1,6,8,11,12$ & $1,2,3,4,5,6,7,8$ & $1,6,8,12$ & \\
\hline 7 & $1,3,4,6,7,8,12$ & $1,2,3,4,5,7,8,12$ & $1,3,4,7,8$, & \\
& & & 12 & \\
\hline 8 & $1,2,5,6,7,8,9,11$, & $1,5,6,7,8,12$ & $1,5,6,7,8$, & \\
& 12 & 12 & 9,10 & \\
\hline 9 & $2,4,9,10,11$ & $1,9,10,13,14,15$ & 9,10 & \\
\hline 10 & $2,9,10,11$ & $1,9,10,13,14,15$ & 11 & 1 \\
\hline 11 & 11 & $1,5,6,8,9,10,11,12$, & 11 & \\
\hline 12 & $3,4,7,8,11,12$ & $5,6,7,8,12$ & $7,8,12$ & \\
\hline 13 & $2,9,10,11,13,14$, & $13,14,15$ & 13,15 & \\
\hline 14 & 15 & & & \\
\hline 15 & $10,10,11,14,15$ & $13,14,15$ & 14,15 & \\
\hline
\end{tabular}

Table 6: levels of enablers

\begin{tabular}{|l|l|l|l|l|}
\hline $\begin{array}{l}\text { Enable } \\
\text { rs }\end{array}$ & Reachability & Antecedent & $\begin{array}{l}\text { Intersecti } \\
\text { on }\end{array}$ & $\begin{array}{l}\text { Lev } \\
\text { el }\end{array}$ \\
\hline 1 & $1,6,12$ & $1,2,3,4,6,7$ & 1,6 & 6 \\
\hline 2 & 2,4 & $2,3,4$ & 2,4 & 8 \\
\hline 3 & 3 & 3 & 3 & 9 \\
\hline 4 & 2,4 & $2,3,4$ & 2,4 & 8 \\
\hline 5 & $\begin{array}{l}1,3,4,5,6,7,8, \\
12\end{array}$ & 5,8 & 5,8 & 5 \\
\hline 6 & $1,6,12$ & $1,2,3,4,6,7$ & 1,6 & 6 \\
\hline 7 & $3,4,7,12$ & 7,12 & 7,12 & 7 \\
\hline 8 & $\begin{array}{l}1,3,4,5,6,7,8, \\
12\end{array}$ & 5,8 & 5,8 & 5 \\
\hline 9 & $2,4,9,10$ & $1,3,8,9,10,13,14$ & 9,10 & 2 \\
\hline 10 & $2,4,9,10$ & $1,3,8,9,10,13,14$ & 9,10 & 2 \\
\hline 11 & 11 & $1,5,6,8,9,10,11,12,1$ & 11, & 1 \\
& & 3,14 & & \\
\hline 12 & $3,4,7,12$ & 7,12 & 7,12 & 7 \\
\hline 13 & 2,13 & 13 & 13 & 4 \\
\hline 14 & 14,15 & $13,14,15$ & 14,15 & 3 \\
\hline 15 & 14,15 & $13,14,15$ & 14,15 & 3 \\
\hline
\end{tabular}

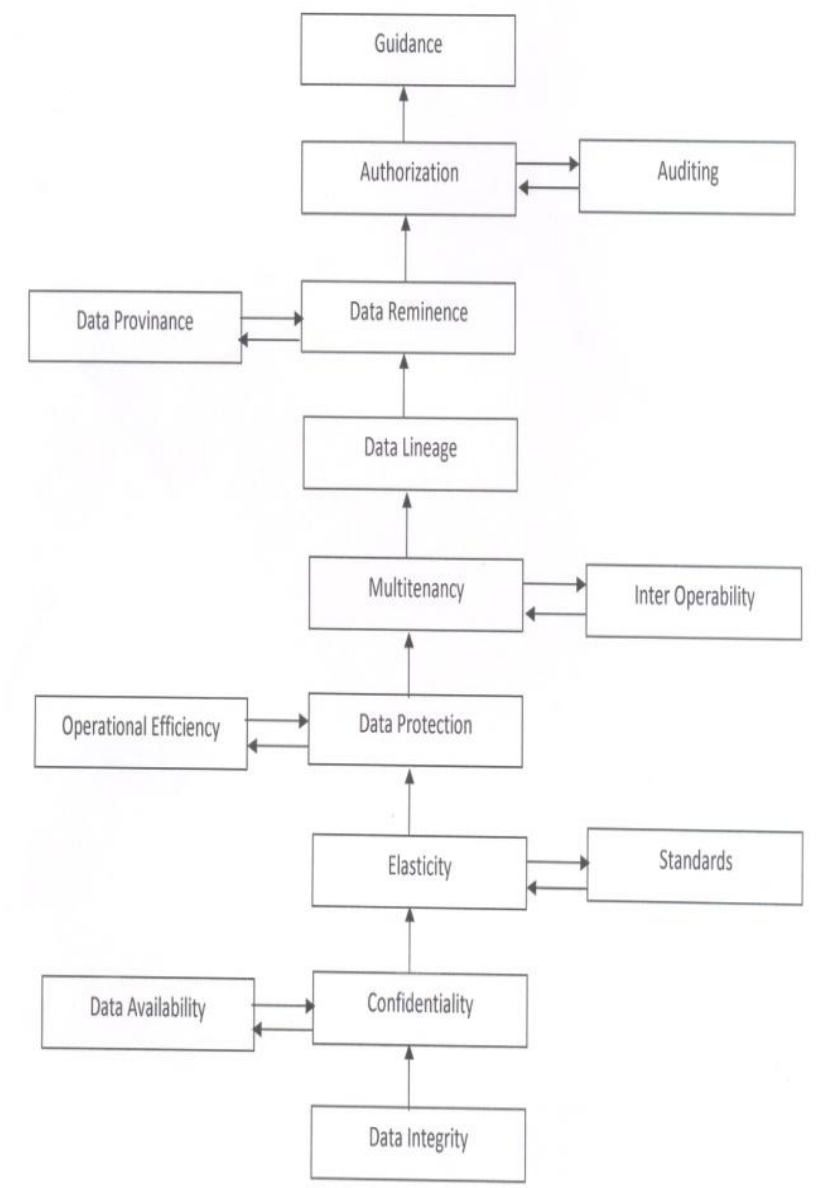

Figure1. Fuzzy Interpretive Structural Model

\subsubsection{Stagnation Matrix.}

The row sum is taken as driving power; the column sum is taken as dependence power and is represented as R1 \&C1. Final reachability matrix is multiplied to a power of 2 . Here the row sum and column sum is taken as R2 \& $\mathrm{C} 2$. The multiplication process is continued for powers $3,4 \ldots$...etc till a stagnation is reached. Each time row sum and column sum is calculated and tabulated and is shown in Table 7. Row sums are represented by $\mathrm{R} 1, \mathrm{R} 2 \ldots$...tc and co;umn sum is represented by $\mathrm{C} 1, \mathrm{C} 2 \ldots . .$. etc as shown in Table7. A comparison is made between R1 R2, R2 R3,R3 R4,R4 R5,R5 R6 and so on until the rank of the driving power and dependence power remain $s$ the same, i.e. maximum to minimum value of the driving power remains the same for 
Table7.Row sum and column sum of the power of matrices

\begin{tabular}{|c|c|c|c|c|c|c|c|c|c|c|c|c|c|c|c|c|}
\hline & 1 & $\overline{81}$ & R2 & $\mathrm{C} 2$ & R3 & $\mathrm{C} 3$ & $\mathrm{R} 4$ & $\mathrm{C} 4$ & R5 & $\mathrm{C} 5$ & R6 & C6 & R7 & C7 & R8 & $\mathrm{C} 8$ \\
\hline 1 & 1 & 8 & 58 & 54 & 340 & 340 & 2024 & 2079 & 12147 & 12577 & 73079 & 75819 & 17.2768 & 16.6447 & 9.0064 & 8.6822 \\
\hline 2 & 5 & 8 & 32 & 51 & 203 & 300 & 1242 & 1750 & 7495 & 10315 & 45116 & 61381 & 10.7142 & 1.9284 & 5.5862 & 6.1882 \\
\hline 3 & 7 & 6 & 44 & 36 & 268 & 219 & 1618 & 1335 & 9741 & 8102 & 58619 & 48991 & 13.6411 & 11.3694 & 7.1107 & 5.9396 \\
\hline 4 & 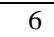 & 0 & 39 & 51 & 247 & 308 & 1510 & 1841 & 9113 & 11015 & 54857 & 66085 & 13.0862 & 14.2473 & 6.8224 & 7.4206 \\
\hline 5 & 9 & 2 & $\overline{59}$ & 8 & 366 & 44 & 2228 & 266 & 13465 & 1636 & 81172 & 10011 & 21.3189 & 2.2392 & 11.1172 & 1.1738 \\
\hline 6 & 5 & 8 & 31 & 54 & 181 & 340 & 1076 & 2079 & 6466 & 12577 & 38958 & 75819 & 7.9523 & 17.8563 & 4.1468 & 9.3112 \\
\hline 7 & 6 & 8 & 43 & 50 & 271 & 306 & 1643 & 1857 & 9895 & 11022 & 59569 & 67681 & 12.8591 & 15.3758 & 6.7049 & 8.022 \\
\hline 8 & 9 & 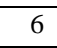 & 56 & 36 & 336 & 222 & 2024 & 1370 & 12207 & 8375 & 73575 & 50826 & 15.2153 & 10.556 & 7.9346 & 5.5174 \\
\hline 9 & 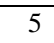 & 7 & 21 & 38 & 108 & 206 & 628 & 1163 & 3762 & 6779 & 22623 & 40195 & 4.7913 & 10.1845 & 2.4968 & 5.284 \\
\hline 10 & 4 & 6 & 15 & 29 & 69 & 142 & 381 & 743 & 2052 & 4129 & 13510 & 23862 & 2.9199 & 6.1021 & 1.5212 & 3.1414 \\
\hline 11 & 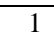 & 10 & 1 & 56 & 1 & 308 & 1 & 1754 & 1 & 10267 & 1 & 61012 & 0.0001 & 14.4186 & 0 & 7.4828 \\
\hline 12 & 6 & 4 & 35 & 20 & 218 & 118 & 1341 & 724 & 8137 & 4439 & 49094 & 27027 & 9.8201 & 6.8214 & 5.1213 & 3.5688 \\
\hline 13 & 7 & 2 & 31 & 5 & 139 & 13 & 681 & 34 & 3641 & 89 & 20639 & 233 & 4.0119 & 0.0436 & 2.0443 & 0.0108 \\
\hline 14 & J & 3 & 19 & 8 & 76 & 21 & 339 & 55 & 1718 & 144 & 9503 & 377 & 2.3725 & 0.0645 & 1.202 & 0.0159 \\
\hline 15 & 4 & 3 & 20 & 8 & 85 & 21 & 369 & 55 & 1770 & 144 & 9381 & 377 & 1.9365 & 0.0644 & 0.9598 & 0.0159 \\
\hline
\end{tabular}

the same enabler. The same process is repeated for the dependence power. A comparison is made between $\mathrm{C} 1 \mathrm{C} 2, \mathrm{C} 2$ C3, C3 C4, C4 C5, C5 C6 and so on. Check for stagnation. A matrix is said to be in stagnation when the dependence power and the driving power ranks remains the same for the same enablers even though matrix is multiplied to higher powers. When comparing $\mathrm{R} 7$ and $\mathrm{R} 8, \mathrm{C} 7$ andC8 the value remains the same (Table8).So the matrix is said to be in stagnation. For example enabler 1 is keeping $11^{\text {th }}$ position in driving power for $7^{\text {th }}$ power of Multiplication of the final reachability matrix and $8^{\text {th }}$ power of multiplication of the final reachability matrix as shown in table8.For the same enabler the rank of dependence power is $13^{\text {th }}$ position for the $7^{\text {th }}$ power of final reachability matrix. This position remains the same for further multiplication.(Table8). Stagnation of the final reachability matrix is obtained for a power of 7 . MATLAB function is used for plotting fuzzy ISM .A three dimensional view of fuzzy ISM for stagnation matrix is shown in fig 2.

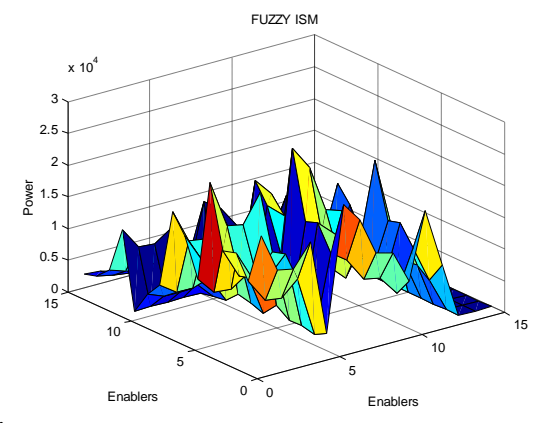

Figure2-Fuzzy ISM for Stagnation.
Table8-Driving power and Dependence powerRanks of enablers for stagnation matrix.

\begin{tabular}{|l|l|l|l|l|}
\hline enablers & R7 & R8 & C7 & C8 \\
\hline 1 & 11 & 11 & 13 & 13 \\
\hline 2 & 15 & 15 & 15 & 15 \\
\hline 3 & 14 & 14 & 14 & 14 \\
\hline 4 & 10 & 10 & 5 & 5 \\
\hline 5 & 13 & 13 & 10 & 10 \\
\hline 6 & 9 & 9 & 12 & 12 \\
\hline 7 & 6 & 6 & 9 & 9 \\
\hline 8 & 12 & 12 & 8 & 8 \\
\hline 9 & 2 & 2 & 3 & 3 \\
\hline 10 & 7 & 7 & 2 & 2 \\
\hline 11 & 4 & 4 & 4 & 4 \\
\hline 12 & 3 & 3 & 11 & 11 \\
\hline 13 & 8 & 8 & 7 & 7 \\
\hline 14 & 1 & 1 & 1 & 1 \\
\hline 15 & 5 & 5 & 6 & 6 \\
\hline
\end{tabular}

\subsection{Development of FMICMAC}

Fuzzy Matrices d' Impacts Croises Multiplication Appliquee a UN Classiment can be used for finding direct and indirect relationship among enablers of cloud computing. Conventional MICMAC analysis considers only binary type of relationship. Fuzzy set theory is introduced to increase the sensitivity of conventional MICMAC analysis. An additional input of possibility of interaction 0 through1 scale is introduced in fuzzy MICMAC. For fuzzy MICMAC analysis the final reachability matrix Table 2 is considered. The sum of the row is taken as driving power and sum of column is taken as dependence power. A graph is plotted taking dependence power on $\mathrm{X}$ axis and driving power on $\mathrm{Y}$ axis, [Figure3]. Based on driving power and dependence power all the enablers under study are classified into four categories. They are (1) Autonomous, (2) Dependent, (3) linkage, (4) Independent. It is observed from the figure 3 that the enabler 1has driving power 9 and dependent power 7.1. The first cluster is known as autonomous having low dependence power and low driving power. Since both the powers are weak the enablers are considered as weak one. Second cluster is dependent, having low driving power and high dependence 
power. Third cluster is linkage having high driving power and dependence power. Fourth cluster is Independent having high driving power and low dependence power. By making a study on above categories it is find that autonomous element i.e. the enablers in the autonomous region is very weak and it doesn't influence the system.

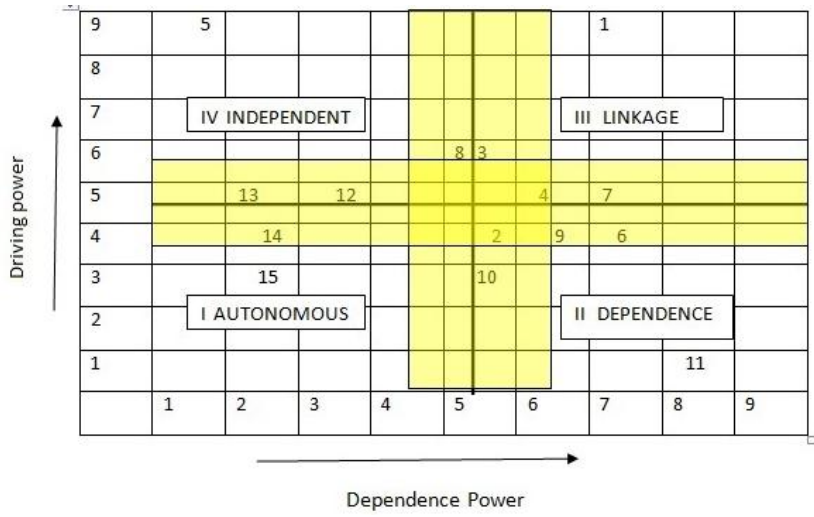

Figure3-Driving power and dependence diagram

So autonomous elements can even be disconnected from the system. The dependent, linkage and independent clusters are very important. These three cluster elements are strongly interrelated and it influence the system as a whole.

\section{RESULTS AND DISCUSSION}

In the selected enablers 14 and 15 are coming under autonomous. Autonomous elements are very weak so it can even be eliminated from the system. The second cluster elements are 2,6,9,10and 11.They are having high dependent power and small driving power and are coming under dependent. The elements $1,3,4$ and 7 is coming under $3^{\text {rd }}$ cluster linkage. They are considered as very powerful enablers which can affect the system. These enablers should be handled carefully. Elements 5,8,12and 13are under $4^{\text {th }}$ cluster- independent category. They have high driving power and low dependence power. They will also affect the system. In fuzzy MICMAC analysis a "transition region" is also considered (Pramod \&Banwet,2012). Transition region is shown in yellow color. Transition region is due to influence of fuzziness. The elements in the transit region have an affinity to jump other regions. Here the elements $2,3,4,6,7,8,9,10,12,13$, and 14 are in the transition region. These elements have tendency to move to nearest region. So the prediction of elements in the four clusters may vary depending on the fuzziness. Elements having high driving power and dependence power are the most important enablers. Dependence power and driving power direct some valuable insight about the importance and interdependence of enablers within a system.

\section{CONCLUSION.}

The research work pinpoints the impact of various enablers of cloud computing by making Fuzzy ISM analysis. The model i.e. FISM model is generated using MATLAB. from which the interrelationship between the enablers can be identified there by necessary steps can be taken to improve the presence of the enablers. In this paper, fifteen elements are selected as enablers and proved by analysis that all the fourteen enablers from fifteen are important. Fuzziness among the interrelationship is studied .Cloud computing is an automated, pay as you go service through a web browser. Flexibility of cloud computing is very high .Structural flexibility of the enablers is derived from a graph relating dependence power and driving power i.e. with FMICMAC analysis. The enablers affecting the system can be selected so as to improve the quality of cloud computing services. Cloud service is said to be portable if we can get service among countries.

\section{REFERENCES}

[1] Tim Mather, Subra Kumaraswamy, Shahed Latif, "Cloud Security and Privacy-AnEnterprise Perspective on Risks and Compliance" O Reilly

[2] Wang.C and Wulf W. A., "Towards a framework for security measurement", 20th National Information Systems Security Conference, Baltimore, MD, Oct. 1997, pp. 522-533.

[3] Savola.R and Abie.H, "Development of measurable security for a distributed messaging system," International Journal on Advances in Security, Vol. 2, No. 4 (2009), 2010.

[4] Jaquith. A, "Security metrics: replacing fear, uncertainty and doubt,"Addison-Wesley, 2007.

[5] Gadia.S, "Cloud computing: an auditor's perspective," ISACA Journal, Vol. 6, 2009

[6] Gellman.R, "Privacy in the clouds: risks to privacy and confidentiality from cloud computing," World Privacy Forum (WPF) Report, Feb. 23, 2009.

[7] Cloud Security Alliance, "Top threats to cloud computing", Version 1.0. Downloaded from: www.cloudsecurityalliance.org [July 4, 2010].

[8] Cloud Security Alliance. www.cloudsecurityalliance.org [July 4, 2010].

[9] Mandal.A, Deshmukh.S, Vendor selection using interpretive structural modeling (ism). International Journal of Operations and Production Management, 1994, 14(6): 52-59.

[10] Sage.A, Interpretive Structural Modeling: Methodology for Large-scale Systems, 91-164. McGraw-Hill, New York, 1977

[11] Warfield.J. Developing interconnection matrices in structural modeling. IEEE Transactionsons on Systems, Man and Cybernetics, 2005, 4(1): 81-67.

[12] Wang.C, "Forrester: A close look at cloud computing security issues," http://www.forrester.com/ securityforum $2009,2009$.

[13] IDC, "It cloud services user survey, pt.2: Top benefits \& challenges," http://blogs.idc.com/ie/?p=210, 2008.

[14] Zetta, "Zetta: Enterprise cloud storage on demand," http://www.zetta.net/, 2008.

[15] Chen.P, Lee.E, Gibson.G, Katz.R, and Patterson.D, "RAID: High performance,reliable secondary storage," ACM Computing Surveys (CSUR), vol. 26, no. 2,pp. 145-185, 1994.

[16] Yahoo!, "Hadoop distribted file system architecture," http://hadoop.apache.org/common/docs/current/hdfs design.html, 2008.

[17] Dwork.C et al., "Differential privacy," LECTURE NOTES IN COMPUTER SCIENCE, vol. 4052, p. 1 , 2006.

[18] Dwork.C, "Differential privacy: A survey of results," 
Lecture Notes in Computer Science, vol. 4978, p. 1, 2008.

[19] Dean. J and Ghemawat.S, "MapReduce: simplified data processing on large clusters," in Proceedings of the 6th conference on Symposium on Opearting Systems Design \& Implementation-Volume 6 table of contents, 2004, pp. $10-10$.

[20] Bardin, J"Security Guidance for Critical Areas of Focus in Cloud Computing," www. cloudsecurityalliance.org/ guidance/csaguide.pdf, 2009.

[21] Hwang, K G. Fox, and Dongarra.J, Distributed Systems and Cloud Computing: Clusters, Grids/P2P, and Internet Clouds, Morgan Kaufmann, to appear, 2010.

[22] Nick J, "Journey to the Private Cloud: Security and Compliance," tech. presentation, EMC, Tsinghua Univ., 25 May 2010.

[23] Rittinghouse $\mathbf{J}$ and Ransome.J, Cloud Computing: Implementation, Management and Security, CRC Publisher, 2010

[24] "Gartner Says Cloud Computing Will Be As Influential As E-business". Gartner.com. Retrieved 2010-08-22.

[25] Ravi.V. and Shankar. R. (2005), Analysis of interactions among the barriers of reverse logistics, Technological Forecasting and Social Change, 72(8): 1011-1029.
[26] Thakkar. J.,Kanda.A. and Deshmukh, S.G. (2008), Interpretive Structural Modeling (ISM) of IT-enablers for Indian

[27] SushantaTripathy, SadanandaSahu, Pradip Kumar Ray, (2013) "Interpretive Structural Modelling for Critical Success Factors of $R \& D$ Performance in Indian Manufacturing Firms", 'Journal of Modelling in Management', Vol. 8 ,No: 2

[28] Pramod and.Banwet D.K (2010), Interpretive structural modeling for understanding the inhibitors of a telecom service supply chain. (IEOM) (Dhaka, Bangladesh), Jan 9-10, 2010 .

[29] Rajesh Attri, Nikhil Devand and Vivek Sharma (2013), Interpretive Structural Modelling (ISM) approach: An Overview, Research Journal of Management Sciences, Vol.2, No. 2, pp 3-8.

[30] B.P. Sharma ,M.D. Singh , Neha 2012,"Knowledge Sharing Barriers: An Approach of Interpretive Structural Modeling", 'The IUP Journal of Knowledge Management', Vol.X, No.3, , pp. 35-52

[31] T .Ambika Devi Amma, V.R Pramod. And N Radhika. ;. MCDM Approach for the Adoption of Best Cloud, International Journal of Computer Applications. Vol 63; issue 15,pp:20-26,January 2013 